\title{
The Roles of the Speed and Accuracy of Morphological Processing in the Reading Comprehension of Spanish- Speaking Language Minority Learners
}

\author{
Jungjun Park (Corresponding author) \\ Department of Communication Sciences and Disorders, Baylor University \\ PO Box 97332, Waco, TX 76798, United States \\ Tel: 1-254-710-3289_E-mail: jungjun_park@baylor.edu \\ Rebecca Wiseheart \\ Department of Communication Sciences and Disorders, St. John's University \\ 8000 Utopia Parkway, Queens, NY 11439, United States \\ Tel: 1-718-990-2709_E-mail: wisehear@stjohns.edu \\ Michaela Ritter \\ Department of Communication Sciences and Disorders, Baylor University \\ PO Box 97332, Waco, TX 76798, United States \\ Tel: 1-254-710-4745_E-mail: michaela_ritter@baylor.edu
}

Received: 19-08-2013

doi:10.7575/aiac.ijalel.v.3n.1p.12
Accepted: 27-09-2013

Published: 01-01-2014

URL: http://dx.doi.org/10.7575/aiac.ijalel.v.3n.1p.12

This study was supported by two intramural grants from the Vice Provost for Research at Baylor University (Young Investigator Development Program and University Research Committee) awarded to the first author.

\begin{abstract}
This study examines morphological awareness performance in 27 low-SES Spanish-English bilingual students in Grades 4 through 7. Given that 1) reading fluency is a strong predictor of reading comprehension and 2) bilingual students with poor comprehension are often slow, albeit accurate readers, the primary goal of this study was to investigate the extent to which speed of morphological processing contributes to both reading fluency and reading comprehension in bilinguals. First, comparisons of accuracy and response times indicated that monolinguals significantly outperformed bilinguals on every measure. Further, hierarchical regression analyses showed that morphological processing speed makes significant, unique contributions to both text reading fluency and reading comprehension which are at least equal to those made by morphological processing accuracy. These results underscore the important role of morphological processing efficiency in reading comprehension and suggest that interventions targeting the speed of morphological processing may improve reading comprehension skills for bilingual students.
\end{abstract}

Keywords: Morphological awareness, language-minority students, reading comprehension, reading fluency

\section{Introduction}

\subsection{Overview}

The majority of American children who fail to meet public education standards in reading are children who either 1) live in poverty or 2) come from minority language households and are learning to speak English at the same time they are learning to read it (Lesaux, 2006); unfortunately, membership in the second category often overlaps with membership in the first category. These populations are at high risk for late emerging reading difficulties, especially in the area of reading comprehension (August \& Shanahan, 2006; Kieffer \& Lesaux, 2012; Lesaux \& Kieffer, 2010).

The enrollment of "language-minority" learners of English who are bilingual but with limited English proficiency has been increasing in early child education programs nationwide (Hernandez, Denton, \& Macartney, 2007). Achievement data suggest that even though typically developing language-minority learners from low-income families in the primary grades can develop grade-appropriate word reading skills, their reading comprehension scores are often well below average for their grade-level (Menken, 2008). Indeed, these bilingual learners not only lag far behind their peers, but the gaps grow as children advance through the upper grade levels (Reardon \& Galindo, 2006). Thus, understanding which components of reading comprehension are unique to bilingual students is critical to the task of creating high-quality reading education and effective intervention strategies.

Towards that goal, our primary focus in this study is on a particular dimension of metalinguistic knowledgederivational morphological awareness - that is now understood to be important for reading comprehension (Deacon, 
2011; Deacon \& Kirby, 2004; Roman, Kirby, Parrila, Wade-Woolley, \& Deacon, 2009), especially in the later stages of reading development (Carlisle, 2000). We sought to investigate the nature and extent of the relationship between derivational morphological awareness and bilingual children's reading skills. Specifically, we examined the unique and distinct contributions of the two constructs of morphological awareness (i.e., accuracy and speed) to reading fluency and reading comprehension for Spanish-English speaking bilingual learners from families of low socioeconomic status (SES).

\subsection{Relationships between morphological awareness and reading skills}

In recent years researchers have given increasing attention to the cognitive underpinnings of word decoding and the importance of two relevant metalinguistic abilities for successful word-level reading: phonological awareness and morphological awareness. Phonological awareness refers to the ability to recognize, identify, and manipulate phonological units such as syllables, rimes, and phonemes and its pivotal role in the development of word reading is now clearly established in the literature and represents the most robust cause of early reading failure (Park \& Lombardino, 2012; Park, Lombardino, \& Ritter, 2013; Snow, Burns, Griffin, 1998; Wagner \& Torgesen, 1987). The past decade has seen a resurgence of evidence that the ability to manipulate the internal structure of words (i.e., morphological awareness) is significantly related to reading skills beyond phonological awareness (Carlisle, 1995; Deacon \& Kirby, 2004; Fowler \& Liberman, 1995; Roman et al., 2009). Morphological awareness refers to the metalinguistic, conscious understanding that words are compiled of individual morphological units (i.e., morphemes) which can be analyzed, synthesized, and manipulated in various ways (Carlisle, 1995; Derwing, Smith, \& Wiebe, 1995; Kuo \& Anderson, 2006).

Morphological units can be inflectional or derivational. Inflectional morphemes signal grammatical relationships such as plurality, possessive, and past tense (e.g., girl-s, girl-s, walk-ed), whereas derivational morphemes form new words by changing the meaning of the root word (e.g., happy $\rightarrow$ un-happy) and often its grammatical category (e.g., home-less is the adjective form of the noun home). According to Koda, Takahashi, \& Fender (1998), morphological composition or decomposition is clearly more systematic for inflectional morphemes than derivational morphemes. In other words, inflectional formation is straightforward since there is a one-to-one correspondence between inflectional morphemes and the distinct grammatical functions (e.g., '-ed' always signals past tense), whereas derivational formation sometimes requires sophisticated knowledge of fairly complex one-to-many correspondence between morphemes and their meanings (e.g., noun formation through multiple suffixes such as -ance, -ment, -tion, -ity, -al, or negative word formation through multiple prefixes such as dis-, a-, in-, im-, ir-, un-, anti-, non-).

Although limited in quantity and scope, the current research on morphological awareness with monolingual Englishspeaking students above third grade shows that morphological awareness is a significant predictor of both word reading (Carlisle, 2000; Carlisle \& Katz, 2006; Fowler \& Liberman, 1995; Roman et al., 2009; Singson, Mahony, \& Mann, 2000; Verhoeven, Baayen, \& Schreuder, 2004) and reading comprehension (Carlisle, 2000; Deacon \& Kirby, 2004; Nagy, Berninger, \& Abbott, 2006; Tong, Deacon, Kirby, Cain, \& Parilla, 2011) even when the confounding effects of phonological awareness and word level reading skills are controlled. Of note, Carlisle (2000) found that morphological awareness skills accounted for $43 \%$ and $55 \%$ of variance in reading comprehension for third graders and fifth graders, respectively. In the same vein, several recent bilingual studies have found that morphological processing skills of bilingual children are significantly lower than those of English-speaking monolingual controls (Carlo et al., 2004) and reading of derived words and performance on morphological awareness tasks correlate strongly with both word reading (Carlisle, 1995; McBride-Chang, Shu, Ng, Meng, \& Penney, 2007; Zhang et al., 2010) and reading comprehension in bilingual children (Abu-Rabia, Share \& Mansour, 2003; Kieffer \& Lesaux 2008, 2010; McBride-Chang et al., 2003; Nagy, Berninger, \& Abbott, 2006; Nagy, Berninger, Abbott, Vaughan, \& Vermeulen, 2003; Pasquarella, Chen, Lam, Luo, \& Ramirez, 2011, Ramirez, Chen-Bumgardner, Geva, \& Kiefer, 2010; Shu, McBride-Chang, Wu, \& Liu, 2006; Zhang \& Koda, 2012).

Though the precise relationship between morphological awareness and reading comprehension is still unclear (Kuo \& Anderson, 2006), one possible explanation is that morphological decomposition, a process of parsing a polymorphemic word into a stem and constituent morphological affixes, is a critically important skill by which children can decipher the meaning of previously untaught words (Carlisle, 2007; Taft \& Kougious, 2004). Once a base word and other affixes in a derived word are efficiently decomposed and recognized (e.g., internationally $\rightarrow$ inter-, -nation-, -al-, -ly), a synthesis of the meaning and grammatical functions of these morphological units will facilitate lexical inference (Koda, 2008). Thus, explicit morphological awareness is known to be one of the determinants of efficient lexical access at word- level (through morphological decomposition) that contribute to text- level understanding (reading comprehension). A further possible explanation is that morphological awareness supports reading comprehension by allowing the reader to quickly and efficiently extract semantic and syntactic information from derivational morphology, thereby freeing up cognitive resources for higher level reading comprehension processes, such as making textual inferences and constructing mental models (Kuo \& Anderson, 2006; Kieffer et al., 2013). For example, knowledge that words with a common root share the same lexical core meaning would facilitate vocabulary learning and semantic inference (i.e., beauty-beautifulbeautify), as would knowledge of the various derivational morphemes expressing various functional or lexical meanings such as agent (i.e., teach-er, magic-ian), lexical relations (i.e., clue-less, dis-like), or part-of-speech (insert-ion, hand-ful). Academic textbooks above third grade are replete with derivationally complex words. Students in upper elementary grades are exposed to an increasing number of these morphologically complex unfamiliar words; indeed, by 5 th grade, approximately $40 \%$ of new words children encountered in academic texts are polysyllabic derived words (Nagy, Osborn, 
Winsor, \& O'Flahavan, 1993). Hence, the relationship between morphological processing and reading achievement is one that may not be apparent in younger children but strengthens as children progress in school (Tong et al., 2011). Thus, to contribute to a growing body of research morphological underpinnings of reading, we focus on derivational morphology, which becomes increasingly important after Grade 3 once children begin "reading to learn".

\subsection{Limitations in previous research}

Several methodological issues limit our current understanding of how morphological awareness contributes to reading comprehension. First, there have been few systematic approaches to investigate the multifaceted aspects of morphological processing skills and their impacts on reading: the constructs of accuracy and speed. Unfortunately, most of morphological awareness research to date has focused primarily on the accuracy component of explicit morphological awareness tasks and understanding its relationship with reading skills. The reason for this is undoubtedly that measurement of speed of morphological processing present additional challenges to the researcher, who must use a software program and related devices while controlling for various technical issues in the design of experiments. Though several researchers have used timed reading of morphologically complex words as an indicator of morphological awareness, to our knowledge, only one study has directly investigated the role of speed of morphological processing (Leong, 2000). Using a computerized morphological awareness task (e.g. base-form production), Leong (2000) found that slower students had a tendency to perform lower on a standardized spelling test. Thus, there remains a dearth of evidence regarding the role of morphological processing speed in reading outcomes. In the present study, we used computerized multiple experimental formats for measuring both accuracy and speed components of morphological processing. The importance of rapid morphological processing is in line with Perfetti's verbal efficiency theory (Perfetti, 1988), which emphasizes a strong association between speed of accurate word reading and text comprehension. Similarly, our approach implicates not only explicit awareness of derivational morphology, but also automaticity or efficiency of morphological processing as being intricately involved in reading comprehension.

Secondly, only a few bilingual studies (Goodwin et al., 2011; Kieffer, Biancorosa, \& Macilla-Martinez, 2013; Ramirez, et al., 2011) have focused on the relationship between derivational morphology and outcome measures of text level reading fluency. Thus, it is still unknown whether or not morphological awareness has effects on reading efficiency beyond the lexical level (Keiffer, et al., 2013). The few studies examining the effects of morphological awareness on text level fluency in Spanish-speaking bilingual children report mixed results. While Ramirez and her colleagues (2011) found a direct relationship between morphological awareness and reading fluency, Goodwin et al. (2011) found the relationship to be mediated by vocabulary. Most recently, Kieffer and colleagues (2013) showed that morphological awareness made an indirect contribution to reading comprehension through both vocabulary and text fluency, but not via word reading fluency, implicating that morphological awareness may affect single word reading differently from reading of connected text. Given the well-established relationship between text reading fluency and reading comprehension (Dowhower 1987; Fuchs, Fuchs, Hosp, \& Jenkins, 2001; Strong, Wehby, Falk, \& Lane, 2004; Tractenberg, 2002), along with the fact that over $60 \%$ of bilingual readers demonstrate slow yet accurate reading performance (Lesaux \& Kieffer, 2010), understanding the effects of morphological awareness skills on reading fluency in bilinguals clearly has far-reaching practical implications. Based on the conjecture that fluent text reading would require rapid morphological decomposition of words so that the visual analysis of the constituent morphemes can be mapped into lexical representation within minimal time, we hypothesize that that the two constructs of morphological processing (i.e., accuracy and speed) are dissociable and have distinct effects on reading fluency.

Finally, previous research has primarily used tasks in which the test items were presented only orally rather than in written form. Given that explicit knowledge of printed morphemic units is an important construct of morphological awareness and the association between morphological awareness and literacy skills would be most clearly demonstrated when the test items are presented in written form, studies employing written morphological awareness tasks are warranted. To better understand the impact of graphomorphological awareness (i.e., morphological awareness as it relates to written language; Nagy, Kuo-Kealoha, Wu, Li, Anderson, \& Chen, 2002) on reading outcomes, we employed two written production tasks of morphological awareness: Morpheme Blending and Morpheme Generation.

\subsection{The present study}

To summarize, it has been established that morphological awareness predicts reading comprehension in bilingual learners and this relationship is probably mediated by vocabulary. It is also well established that 1) language-minority learners are often accurate but slow readers and 2) deficits in reading speed can lead to deficits in reading comprehension. So, in addition to poor morphological awareness, slow processing of written morphology may also contribute to reading comprehension difficulties in these children.

The current study was designed to investigate the contribution of derivational morphological knowledge to text reading fluency and comprehension focusing on both accuracy and speed (i.e., processing latency) measures in a group of Spanish-speaking language-minority learners in the upper elementary grades (i.e., Grade 4 to 7 ) using two experimental written morphological awareness tasks. Specifically, we examined the extent to which the contributions of these two constructs of morphological processing to reading fluency and reading comprehension are separable and distinct in these bilingual students. The present study addresses several methodological issues in previous studies by employing only written morphological tasks rather than oral ones and by using chronometric production tasks. Analyzing both accuracy and reaction time (RT) scores generated by two computerized experimental procedures, this study was designed to address the following research questions: 
1. Controlling for grade, how do the measures of accuracy and speed of morphological processing in Spanishspeaking bilingual language-minority learners compare to that of English-speaking monolingual controls?

2. To what extent does the accuracy of morphological processing affect bilingual language-minority learners' performances in reading fluency and reading comprehension over and above the contributions made by nonverbal IQ, grade, phonological awareness, vocabulary, and word-level reading?

3. To what extent does the speed of morphological processing affect bilingual language-minority students' performances in reading fluency and reading comprehension over and above the contributions made by nonverbal IQ, grade, phonological awareness, vocabulary, and word-level reading?

\section{Method}

\subsection{Participants}

A total of 54 children who were enrolled in local public schools in a southwestern area of the U.S. participated in this study. Children were recruited for one of two groups: Spanish-English speaking bilingual students (BL group, $\mathrm{n}=27$ ) and monolingual controls speaking English only (ML group, $n=25$ ), who were matched to bilingual participants on age, gender, and nonverbal IQ as closely as possible. Participants ranged in age from 9;3 (years;months) to 13;1 ( $M=11 ; 6$, $S D=1 ; 4)$ and were enrolled in fourth through seventh grade. The average grade was $5 ; 5(S D=1 ; 4)$. As noted earlier, the choice of grades 4 to 7 is linked to the children's extensive exposure to written texts containing a plethora of morphological complex words and the pedagogical emphasis on explicit morphological instruction about target derivational morphemes in these grades. Informed consent was obtained in compliance with our institutional review board's guideline for the protection of human subjects. Each participant was compensated $\$ 20$ for their participation.

General criteria. Participants in both groups had to meet the following inclusion criteria: (a) no reported history for frank neurological damage, and emotional/psychological disability; (b) normal nonverbal intelligence skills; (c) no identified needs for special education per parent report; (d) scores within the normal range on measures of English oral language in order to guarantee that they had appropriate language skills for participating in experimental tasks in English; and (e) passed a pure-tone hearing screening at $25 \mathrm{~dB}$ HL (i.e., American National Standards Institute, 1989) at 1000, 2000, and $4000 \mathrm{~Hz}$ at the time of testing. The Test of Nonverbal Intelligence - 4th Edition (TONI-4; Brown, Sherbenou, \& Johnsen, 2010) was administered to assess participants' cognitive abilities. For children in the BL group, the group mean was $101.7(S D=11.81)$ and for those in the ML group, the mean was $107.2(S D=12.83)$. Participants' receptive and expressive spoken language skills in English were assessed using the four core subtests of the Clinical Evaluation of Language Fundamentals-4 (CELF-4; Semel, Wiig, Secord, 2004), including Concepts and Following Directions, Recalling Sentences, Formulating Sentences, and Word Classes. The test results indicated that all children possessed language skills within the normal range as indexed by standard composite language scores. For children in the BL group, the group mean was $94.92(S D=8.85)$, and for those in the ML group, the group mean was $103.11(S D=$ 12.83). Participants' characteristics on demographic and background variables are shown in Table 1.

Table 1. Participants' characteristics on demographic and background variables

\begin{tabular}{|c|c|c|}
\hline Variables & BL group $(n=27)$ & CA group $(n=25)$ \\
\hline Gender (male/female) & $13 / 14$ & $12 / 13$ \\
\hline Parental SES ${ }^{\mathrm{a}}$ & $3.1(1.29)$ & $7.2(2.51)$ \\
\hline Age (year;months) ${ }^{\mathrm{b}}$ & $10 ; 8(1 ; 5)$ & $11 ; 2(1 ; 4)$ \\
\hline TONI $-4^{\mathrm{b}}$ & $101.7(11.81)$ & $107.2(12.83)$ \\
\hline TVIP $^{\mathrm{b}}$ & $94.95(16.17)$ & N/A \\
\hline CELF-4 (CLS) ${ }^{\mathrm{b}}$ & $96.92(11.11)$ & $103.11(12.83)$ \\
\hline \multicolumn{3}{|l|}{$\mathrm{n}$ for each grade } \\
\hline 4th grade & 10 & 11 \\
\hline 5th grade & 8 & 8 \\
\hline 6th grade & 8 & 5 \\
\hline 7th grade & 1 & 1 \\
\hline \multicolumn{3}{|c|}{$\begin{array}{l}\text { Note. TONI-4 = Test of Nonverbal Intelligence }-4 \text { th Edition; TVIP }=\text { Test de Vocabulario en } \\
\text { Imagenes Peabody. CELF-4 (CLS) = Composite Language Score on the Clinical Evaluation of } \\
\text { Language Fundamentals-4. } \\
{ }^{a} \text { Measured by Hollingshead (1975)'s 9-point Occupational Status Scale (means and standard } \\
\text { deviations). }{ }^{b} \text { mean (standard deviation). }\end{array}$} \\
\hline
\end{tabular}

Bilingual participants. A total of 27 Spanish-speaking bilingual children (13 males, 14 females) who met the eligibility criteria participated in this study. First, these children had experienced early sequential bilingualism. Early sequential bilinguals are defined as children who were dominantly exposed to a single minority language from birth as a first and primary language (L1) and began to learn L2 (English) as the dominant language after they had been enrolled in English-only instructional programs at age 4 to 6 (Kohnert, Bates, \& Hernandez, 1999; Jia, Kohnert, Collado, \& Aquino-Garcia, 2006). These bilingual participants in our study received formal school instruction in English beginning in Kindergarten and had approximately 4 to 8 years of consistent exposure to English. In their classrooms, use of Spanish was minimal and the focus was not on Spanish language and literacy development. 
Second, participants in the BL group came from families of low-SES. In this study, SES was coded using Hollingshead (1975)'s 9-point Occupational Status Scale for the occupation for the primary income-maker in the household. The Hollingshead Occupational Scale ranges from 1 (menial jobs) to 9 (major professional jobs). The mean SES score for the bilingual subject was $3.1(S D=1.29)$, corresponding to the lower SES category. In addition, $79 \%$ of children in this group were enrolled in their school's free or reduced price lunch program. Third, bilingual participants were required to have standard scores no less than $1 S D$ on a Spanish receptive vocabulary test to rule out the potential for language learning difficulty in their L1. The Test de Vocabulario en Imagenes Peabody (TVIP; Dunn, Padilla, Lugo, \& Dunn, 1986) was administered by two bilingual testers to assess Spanish receptive vocabulary. The TVIP is a standardized single word receptive vocabulary test for Spanish. Norms for the TVIP were developed with Spanish-speaking monolingual students in Mexico and Puerto Rico. The BL group's mean standard score on the TVIP was 94.95, $S D=$ 16.17 (range $=86.7$ to 122 ). Last, these children ranged between the ages of 9;9 and 13;7 (years;months), with a mean age of $10 ; 8(S D=1 ; 5)$. Parental and child interviews indicated that Spanish was the primary language used by the family. Parents' interview also indicated that the majority of participants (i.e., 92\%) were from working-class families who spoke a Mexican dialect of Spanish.

Monolingual participants. Twenty five monolingual controls (12 males, 13 females) came from English-speaking homes. They had not been exposed to other languages either in the home or at school. None of these children had any history of developmental difficulties in the areas of speech, language, reading, or general cognition. These children ranged between the ages of $9 ; 3$ and $13 ; 3$ (years;months), with a mean age of $11 ; 2(S D=1 ; 4)$. The ethnic make-up of the control group participants was 24 (96\%) Anglo and 1 (4\%) Asian American. The Hollingshead (1975) index of SES indicated a predominantly upper middle-class sample $(M=7.2 ; S D=2.51)$.

Independent sample $t$-test revealed no significant differences between the two groups for all nonverbal IQ and chronological age. However, because we deliberately selected bilingual participants from low SES families, participating families' SES was significantly higher in the CA group than the BL group $(p<.01)$.

\subsection{Measures}

To answer our first research question, participants in both groups were administered a battery of experimental tasks of morphological awareness. Additionally, bilingual subjects were administered a battery of standardized tests of reading fluency (word- and text-level) and reading comprehension along with three control variables that were used in the regression analyses on literacy measures (i.e., receptive vocabulary, phonemic awareness, and untimed word reading accuracy).

\subsubsection{Morphological awareness}

Two computerized written tasks of morphological awareness were used to measure children's knowledge of English derivational morphology: Morpheme Blending and Morpheme Generation. Both tests were run on a software program, DirectRT version 2012 (Empirisoft Corporation, 2012) installed in an IBM laptop computer (Dell Latitude 6400). For both tasks, each participant was seated in a normally illuminated room facing a 21-inch computer monitor. Participants wore a set of headphones (Sony MDR-7506), through which detailed oral instructions and examples were provided. These oral instructions were recorded by a female native speaker of American English in a sound-proof room. All of the written trial and testing items were presented on the monitor using 24-point Arial font. A highly sensitive microphone attached to the headphone detected the participants' verbal responses and relayed RTs to the computer. The subjects were instructed to say the words as quickly as possible without sacrificing accuracy. For both tasks, a set of 6 practice trials were provided. The examiner repeated these practice items as many times as needed until the participant completely understood the task. Accidental voice key activations, voice key failures, or incidental verbal responses were recorded by the tester. Both accuracy scores and RT measures were obtained for each correctly answered trial. Time taken from initial presentation of written stimulus to onset of verbal production was the RT. In order to ensure that these tests measured the participants' morphological awareness rather than vocabulary knowledge and reading skills, all stimuli words were taken from a third grade history textbook. Each trial began with five, 500-ms fixation dots at the center of the monitor and a short beeping sound. The stimulus item immediately followed the dot and remained on the screen for $6000 \mathrm{~ms}$, or until the participant provided a verbal response, whichever was shorter. RTs times longer than these cutoff points were coded as 'no response' and DirectRT presented the next item automatically. The interstimulus interval was $1000 \mathrm{~ms}$ before the presentation of the next fixation dots.

Morpheme Blending. The Morpheme Blending task adopted from Casalis, Colé, and Sopo (2004) measured each participant's morphological combination ability. On this task, two or three incorrectly sequenced morphemes were presented on the computer monitor simultaneously. These morphemes consisted of one base morpheme and one or two derivational affixes (e.g., ly, friend $\rightarrow$ friendly; ble, un, comfort $\rightarrow$ uncomfortable). The participants were instructed to reorder and combine these morphemes to construct a new derivational word, and pronounce the word as quickly as possible. Each participant was provided with 6 practice items, which were followed by the 40 experimental items presented in four experimental blocks of 10 items. Participants received one point for each correctly answered item and the total points were 40. Split-half reliability of the accuracy and scores measured by Spearman-Brown corrected coefficients were adequate for the whole group (Cronbach's alphas $=.86$ and .82 ) and for the BL group (Cronbach's alphas $=.84$ and .81 ) and the ML group (Cronbach's alphas $=.87$ and .82 ), respectively. The 40 testing items are shown in the appendix A.

Morpheme Generation. The second morphology awareness task, Morpheme Generation, was also a written task. This 
task was adapted from the Derivational Suffix Test (Mahony, 1994; Singson, Mahony, \& Mann, 2000), which has been used frequently in the literature (Apel, \& Thomas-Tate, 2009; Carlisle, 1995; Folwer \& Liberman, 1995; Kieffer \& Lesaux, 2012). First, the participants were asked to silently read an isolated base word and then complete an incomplete sentence containing a blank at the end by saying aloud a morphological derivative of the base morpheme (e.g., "humor", "His joke was very __"). For each trial, both the base word and the frame sentence were presented simultaneously on a computer monitor. The test comprised 24 written items in addition to 6 practice items. Speed of morphological generation as well as accuracy of the verbal responses was assessed. Each correctly derived word received one point and the total point of this test was 24 . Among these 24 items, only 6 of the answers required a phonological change of the base word (e.g., science $\rightarrow$ scientist) and the remaining items did not. To prevent placing an unnecessary verbal memory load, all of the frame sentences were shortened and grammatically simplified. This task also showed adequate estimates of split-half reliability coefficients for the accuracy and RT scores (with Spearman-Brown correction) for the whole group (Cronbach's alphas $=.81$ and .80 ) and for the BL group (Cronbach's alphas $=.79$ and .78 ) and the ML group (Cronbach's alphas $=.82$ and .81 ), respectively. The 24 testing items are shown in the appendix B.

\subsubsection{Reading measures}

Word-level reading fluency. To assess word reading fluency for single words, a subtest of the Test of Word Reading Efficiency (TOWRE; Wagner, Torgesen, \& Rashotte, 1999a), Version A, was administered: Sight Word Efficiency (SWE). On the SWE subtest, participants are asked to read aloud as many words as possible in a limited time (i.e., 45 seconds). The SWE subtest is a reliable measure of accuracy and speed in reading phonetically regular and irregular words. Split-half reliability coefficients for students age 9 to 13 exceed .90 .

Text-level reading fluency. We administered the Gray Oral Reading Test-4 (GORT-4; Wiederholt \& Bryant, 2001) to assess the text reading fluency. The GORT- 4 consists of 12 reading passages that increase in the length and complexity of sentences, grammatical structures, and vocabulary level. In this standardized, norm-referenced test, reading fluency is represented as a composite score of two components: rate and accuracy. The participants' reading of the passage is timed in seconds (i.e., a measure of rate), and the number of deviations from the printed text while reading (i.e., a measure of accuracy) is recorded. The publisher reports high split-half reliability of .92 for the fluency measures.

Reading comprehension. Students also completed an untimed standardized test of reading comprehension, Passage Comprehension subtest from the Woodcock Reading Mastery Test-Revised (WRMT-R, Form H; Woodcock, 1987), which measured silent reading comprehension. For this subtest, the participants were asked to read a short paragraph silently and provide a missing word to fill in the blank in the printed paragraph. Mean split-half reliability coefficient for students aged 9 to 13 exceeds .09 .

\subsubsection{Control variables}

Scores on the following tests were used as control variables in the regression analyses.

Receptive vocabulary task. We administered the Peabody Picture Vocabulary Test-Fourth Edition Form A (PPVT-4; Dunn \& Dunn, 2006) to assess the participant's comprehension of single words by requiring them to point to a colored picture that corresponds to the word orally presented by the tester. According to the test manual, the PPVT-4 has an excellent average split-half reliability of .93 across age.

Phonemic awareness task. We used the Elision subtest from the Comprehensive Test of Phonological Processing (CTOPP; Wagner, Torgesen, \& Rashotte, 1999b), in which children were asked to listen to a spoken word, delete a syllable or phoneme in either the initial, final, or medial position of the word, then produce the new word. The CTOPP has an average reliability coefficient of 82 .

Untimed word reading accuracy. The Word Identification subtest of the Woodcock Reading Mastery Test-Revised, Form H (WRMT-R; Woodcock, 1987), was selected to control for the effect of word reading accuracy on text-level reading measures. This subtest consists of 106 words that varied in spelling-to-sound regularity and familiarity. Participants are asked to read isolated single words in an untimed manner. Testing is discontinued after six consecutive errors. Students earn 1 point for each correctly pronounced word. The split-half reliability for grades 1 to 9 ranges from .91 to .98 .

\subsection{Procedures and interrater reliability}

The participants were assessed in the spring and the fall of the school year. Both initial screening for inclusion criteria and subsequent testing were conducted by one of five trained graduate research assistants, who were majoring in communication sciences and disorders. These graduate examiners participated in six, two-hour training sessions that included specific instruction on test administration. Testing was administered individually over two sessions in a quiet therapy room. Each session took approximately $75 \mathrm{~min}$ to complete and the order of test administration was counterbalanced.

In order to ensure the quality and fidelity of the research, all testing sessions were supervised by two speech-language pathologists who were certified by the American Speech-Language-Hearing Association (ASHA) for a minimum of $50 \%$ of the time. Additionally, two trained reliability coders checked the raw and standard scores for $50 \%$ of the entire sample and conducted an item-by-item comparison of their respective responses to each item administered in the battery. A reliability score was calculated for each variable by dividing the number of agreements by the number of disagreements plus agreements and multiplying by 100 . Interrater agreement was $95.2 \%$ agreement for raw scores and $98.5 \%$ agreement for standard scores. 


\section{Results}

\subsection{Data treatment and statistical analysis}

Prior to the statistical analyses, the following types of unusable RTs were eliminated. First, RTs obtained from trials in which the participant's vocal response failed to trigger the voice key or accidental extraneous sound activated the voice key were removed. Second, RTs from outlier trials were also removed from the data. In this study, two categories of outlier trials were considered: (1) lower outliers defined as any RTs shorter than $100 \mathrm{~ms}$ and (2) upper outliers defined as RTs that were two standard deviations longer than the mean RT. Thus, 57 out of 3,328 items (1.7\%) were considered as mechanical errors (37 items) or outliers (20 items). After excluding all outliers and unusable RTs associated with mechanical errors, mean RTs for correct responses and accuracy scores (percentage of correct items) were calculated across subjects.

The two groups' accuracy scores were distributed well above the level of chance (i.e., 50\%) for both morphological awareness tasks. Indeed, initial Shapiro-Wilk tests for normality revealed that they were not normally distributed, so an arcsine transformation was applied to the proportions of accurate responses. Similarly, a log transformation was applied to the RT data because statistical examinations of the RT scores revealed that these data were not normally distributed as well. All statistical analyses were performed using the transformed data.

\subsection{Group performance on morphological awareness tasks}

A summary of data for morphological awareness tasks is provided in Table 2, including means and standard deviations for the accuracy and RT responses broken down by group and task.

Table 2. Morphological awareness data (means and standard deviation) in terms of percentage accuracy and reaction times (RTs) for correct responses, $F$-statistics, and effect sizes

\begin{tabular}{|c|c|c|c|c|c|c|c|}
\hline \multirow{3}{*}{$\begin{array}{l}\text { Morphological } \\
\text { awareness tasks }\end{array}$} & \multicolumn{4}{|c|}{ Group } & \multirow{3}{*}{$F^{\mathrm{a}}$} & \multirow{3}{*}{$p$} & \multirow{3}{*}{$\eta_{\rho}^{2}$} \\
\hline & \multicolumn{2}{|c|}{$\mathrm{BL}$} & \multicolumn{2}{|c|}{ ML } & & & \\
\hline & $M$ & $S D$ & $M$ & $S D$ & & & \\
\hline \multicolumn{8}{|l|}{ Morpheme Blending } \\
\hline Accuracy (\%) & 91.65 & 4.35 & 95.43 & 3.69 & 7.765 & .008 & .137 \\
\hline RT & 2574.44 & 639.46 & 1735.68 & 580.95 & 18.159 & .000 & .270 \\
\hline \multicolumn{8}{|c|}{ Morpheme Generation } \\
\hline Accuracy (\%) & 83.73 & 7.79 & 91.00 & 7.67 & 19.624 & .000 & .186 \\
\hline RT & 4520.07 & 950.36 & 3253.76 & 971.92 & 19.908 & .000 & .292 \\
\hline
\end{tabular}

Note. Reaction times (RTs) are in milliseconds. $\mathrm{BL}=$ bilingual group $(\mathrm{n}=25), \mathrm{ML}=$ monolingual controls $(\mathrm{n}=27)$.

${ }^{\mathrm{a}} F$ statistics in the analyses of covariance $\left(d f_{1}=1, d f_{2}=49\right)$.

To test whether the two groups differed on morphological awareness skills, accuracy and RT data were analyzed separately using a one-way analysis of covariance (ANCOVA) in which participants' grade was the covariate. Even though the two groups did not significantly differ in age, participants' grade was covaried because morphological awareness measures have a strong dependence on the amount of exposure to complex words in written text (Carlisle, 2003). Only correct responses were analyzed for RT. An a priori alpha level of .05 was set for the detection of significant group differences and partial eta squared $\left(\eta_{\rho}{ }^{2}\right)$ was calculated to reflect the strength of the significance (Cohen, 1988).

Accuracy Data. Results of one-way ANCOVAs for accuracy scores indicated significant main group effects for both tasks, $F(1,49)=7.765, p=.008$ (Morpheme Blending) and $F(1,49)=19.624, p<.001$ (Morpheme Generation). As expected, even though the two groups' percentage scores had almost reached ceiling for both experimental tasks, the overall performance of the BL group was significantly less accurate than that of the ML group on both morphological awareness tasks under time pressure. Of note, a slightly larger effect size was noted for Morpheme Generation task (i.e., BL: $85.41 \%$ accuracy; ML: $91.65 \%$ accuracy; $\eta_{\rho}{ }^{2}=.186$ ) than Morpheme Blending task (i.e., BL: $91.75 \%$ accuracy; ML: $95.43 \%$ accuracy; $\eta_{\rho}^{2}=.137$ ), suggesting that Morpheme Generation task was more difficult to perform for bilingual participants due to the complexity of generating a new derivational word appropriated for a certain semantic context.

RT Data. Further, one-way ANCOVAs for RT data revealed that there were significant RT differences between the two groups for both Morpheme Blending, $F(1,49)=18.159, p<.001$ (BL group: $M=2574.44, S D=639.56$; ML group: $M$ $=1735.68, S D=580.96$ ), and Morpheme Generation, $F(1,49)=19.9108, p<.001$ (BL group: $M=4372.07, S D=$ 950.36; ML group: $M=3253.76, S D=971.92$ ), indicating that the BL group was significantly slower than the ML group on both tasks. The effect sizes were of small magnitude for both tasks, but the effect for the Morpheme Generation task was slightly larger $\left(\eta_{\rho}^{2}=.312\right)$ than that for Morpheme Blending $\left(\eta_{\rho}^{2}=.270\right)$.

\subsection{Bivariate correlations}

The second and third questions concerned the relationship between bilingual participants' morphological awareness and reading measures. Table 3 presents the means and standard deviations of the BL group on the reading measures and selected control variables. 
Table 3. Means and standard deviations of reading measures and control variables for regression analyses (only for the bilingual participants)

\begin{tabular}{|c|c|c|}
\hline Tasks & $M$ & $S D$ \\
\hline \multicolumn{3}{|l|}{ Reading variables } \\
\hline Word-level fluency (TOWRE) ${ }^{\mathrm{a}}$ & 102.52 & 12.76 \\
\hline Text-level fluency (GORT-4) & 8.56 & 3.01 \\
\hline Reading comprehension (WRMT-R) ${ }^{b}$ & 95.15 & 10.55 \\
\hline \multicolumn{3}{|l|}{ Control measures for regression } \\
\hline Nonverbal intelligence (TONI-4) & 101.70 & 11.81 \\
\hline Receptive vocabulary (PPVT-4) & 96.63 & 15.04 \\
\hline Phonological awareness (CTOPP) & 9.15 & 3.51 \\
\hline Word identification (WRMT-R) & 96.30 & 11.97 \\
\hline \multicolumn{3}{|c|}{ 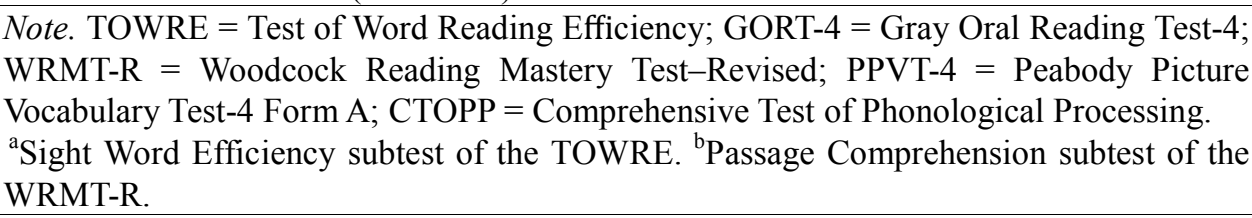 } \\
\hline
\end{tabular}

Table 4 is a matrix of partial intercorrelations, controlling for participants grade, among the measures of reading, morphological awareness, and control variables (e.g., phonological awareness, grade, nonverbal IQ, vocabulary, and word-level reading accuracy).

Modest to high correlations were found between measures of morphological awareness and reading skills and most correlations were significant. The only nonsignificant correlation was noted between word reading fluency and Morpheme Blending accuracy. In particular, accuracy scores for both morphological awareness tasks were significantly correlated with the reading comprehension subtest (i.e., Passage Comprehension), with $r$ 's ranging from .60 to .63.

Slightly smaller but similar strength of correlations were noted between accuracy scores and text reading fluency (i.e., GORT-4 Fluency), with $r$ 's ranging from .51 to .59. Further, the accuracy component of morphological awareness showed somewhat weaker relationship with word reading fluency (i.e., TOWRE SWE) ( $r$ ranging from .37 to .44 ).

Impressively, RT scores on both tests showed significant and negative correlations with all of the reading measures $(r$ ranging from -.41 to $-.66, p \mathrm{~s}<.01)$. It was specifically predicted that the processing latency measures (i.e., RT scores) would show stronger correlations with the reading fluency measures than the accuracy scores. As expected, an inspection of the coefficients revealed that RT scores have significant correlations of highest magnitude with the text reading fluency scores (i.e., GORT-4), $r$ ranging from -.59 to -.66 $(p \mathrm{~s}<.01)$. The correlations between RT scores and the word reading fluency scores (i.e., TOWRE) were significant but not as strong $(r=-.41$ to $-.46, p \mathrm{~s}<.01)$. Of note, the RT scores were more strongly correlated with text reading comprehension $(r=-.57$ to $-.58, p$ s $<.01)$ than word-level reading fluency. RT scores on the Morpheme Generation test tended to have stronger correlations with all three reading measures $(r=-.46$ to $-.66, p \mathrm{~s}<.001)$ than those on the Morpheme Blending task $(r=-.41$ to $-.59, p \mathrm{~s}<.01)$.

\subsection{Hierarchical regression analysis}

A series of hierarchical regression analyses were conducted for the BL group to determine unique variance explained by morphological awareness measures. In order to assess the unique variance accounted for by each construct of morphological awareness, we aggregated performance on the four morphological awareness measures into two composite scores (i.e., Accuracy and RT composites). These composite scores were generated by computing $z$ scores for each task. The $z$ scores for the accuracy and RT measures were then averaged across the tasks to create composite accuracy and RT composite scores, respectively. The order of the variables entered in the regression equation was as follows. The nonverbal IQ scores (i.e., TONI-4) and grade were entered in Step 1. In Step 2, scores on receptive vocabulary task (i.e., PPVT-4) were entered to control for the influence of vocabulary skills in text comprehension and reading fluency. In Step 3, scores on the Elision (CTOPP) were entered to control for the effects of phonological awareness. Composite scores on the morphological awareness tasks were entered in Step 4 interchangeably to evaluate whether it could add to the explanation of variance in reading fluency and reading comprehension over and above the effect of background variables and reading-related predictors (thus there were two separate regression models for each reading outcome). The results of the regression analyses are presented in Table 5 and Table 6 . For each of the three reading variables, we report the standardized beta coefficient from the step at which the predictor was first entered the regression model and the proportion of incremental variance at each step. The bottom two lines show the effect of each morphological awareness variable entered interchangeably at the last step. 
Table 4. Partial conrelation matrix for the bilingual group with school grade in months covaried $(n=27)$

\begin{tabular}{|c|c|c|c|c|c|c|c|c|c|c|c|}
\hline & & 1 & 2 & 3 & 4 & 5 & 6 & 7 & 8 & 9 & 10 \\
\hline 1 & nonverbal intelligence(TONI-4) & $\cdot$ & & & & & & & & & \\
\hline 2 & word reading a ccuracy (WRMT-R/4 & $41^{*}$ & - & & & & & & & & \\
\hline 3 & receptive vocabulary (PPVT-4) & $56^{\circ *}$ & $65^{* *}$ & - & & & & & & & \\
\hline 4 & phonological awareness (CTOPP) & .25 & $.62^{* *}$ & $51^{* *}$ & . & & & & & & \\
\hline 5 & Morpheme Blending (Accuracy) & 21 & $51^{* *}$ & $42^{*}$ & $50^{\circ+}$ & - & & & & & \\
\hline 6 & Morpheme Blending (RT) & -.24 & $-.45^{*}$ & $-.49^{* 4}$ & $-.52^{4+4}$ & -.16 & - & & & & \\
\hline 7 & Morpheme Generation (Accuracy) & .22 & $58 *$ & $.65 *$ & $53^{* *}$ & $-45^{*}$ & $-.60^{4 *}$ & - & & & \\
\hline 8 & Morpheme Generation (RT) & -34 & $-.61^{--}$ & $-67^{* *}$ & $-.59^{*-}$ & -.36 & $.76^{\circ}$ & $-74^{* *}$ & - & & \\
\hline 9 & Word reading fluency (TOWRE) & $50^{\circ}$ & $.75^{*}$ & $.71^{\cdots}$ & $59 *$ & 37 & $-41^{*}$ & $44^{*}$ & $-46^{\circ}$ & - & \\
\hline 10 & Text reading fluency (GORT -4 ) & $41^{\circ}$ & $.72^{* *}$ & $76^{\cdots *}$ & $66^{* *}$ & $51^{*}$ & $-59^{* *}$ & $59^{* *}$ & $-.66^{*}$ & $64^{* *}$ & - \\
\hline 11 & Passage comprehensica (WRMTT-R) & $42^{*}$ & $73^{* *}$ & $23^{* *}$ & $72^{* *}$ & $63^{*}$ & $-.57^{*}$ & $60^{* *}$ & $-.58^{*}$ & $.55 *$ & .79 \\
\hline $\begin{array}{l}\text { Nore } \\
\text { Voc: } \\
\text { Effi } \\
\text { Wo: } \\
p<<\end{array}$ & 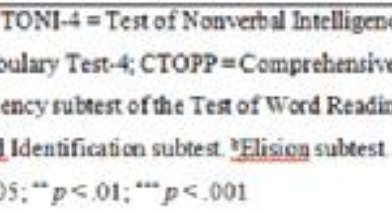 & $\begin{array}{l}\text { Edition } \\
\text { f Phono } \\
\text { iency. }\end{array}$ & $\begin{array}{l}\text { R.MT- } \\
\text { ical PT }\end{array}$ & $\begin{array}{l}\text { Woodoc } \\
\text { sing: GO }\end{array}$ & $\begin{array}{l}-4=G \\
-4=a d i n\end{array}$ & $\begin{array}{l}\text { astery } \\
\text { Onal R }\end{array}$ & $\begin{array}{l}\text {-Revis } \\
\text { ng Tes }\end{array}$ & $\begin{array}{l}\text { PPVT } \\
\text { TOW }\end{array}$ & $\begin{array}{l}\text { Peabo } \\
\text { SWE }=\end{array}$ & $\begin{array}{l}\text { Aeture } \\
\text { te Word }\end{array}$ & \\
\hline
\end{tabular}

Table 5. Results of hierarchical regression analyses predicting reading outcomes

\begin{tabular}{|c|c|c|c|c|c|c|c|}
\hline \multirow[t]{2}{*}{ Steps } & \multirow[t]{2}{*}{ Predictors } & \multicolumn{2}{|c|}{$\begin{array}{c}\text { Word reading } \\
\text { fluency } \\
\text { (TOWRE SWE) }\end{array}$} & \multicolumn{2}{|c|}{$\begin{array}{l}\text { Text reading fluency } \\
\qquad(\text { GORT-4) }\end{array}$} & \multicolumn{2}{|c|}{$\begin{array}{c}\text { Text } \\
\text { comprehension } \\
(\text { WRMT-R) }\end{array}$} \\
\hline & & $\beta$ & $\Delta R^{2}$ & $\beta$ & $\Delta R^{2}$ & $\beta$ & $\Delta R^{2}$ \\
\hline 1. & & & $.08^{*}$ & & $.11^{*}$ & & $.08^{*}$ \\
\hline & Nonverbal IQ (TONI-4) & $.37^{*}$ & & $.38^{*}$ & & $.36^{*}$ & \\
\hline & Grade & .26 & & .06 & & .11 & \\
\hline 2. & Receptive vocabulary (PPVT-4) & $.62^{*}$ & $.15^{*}$ & $.79^{* *}$ & $.29^{* *}$ & $.74^{* *}$ & $.31^{* *}$ \\
\hline 3. & Phonemic awareness (CTOPP) & $.47^{* *}$ & $.14^{* *}$ & $.41^{* *}$ & $.11^{* *}$ & $.44^{* *}$ & $.07^{*}$ \\
\hline $4 a$ & Composite accuracy (MA) & .05 & .02 & $.33^{* *}$ & $.09^{* *}$ & $.29^{* *}$ & $.07^{* *}$ \\
\hline $4 \mathrm{~b}$. & Composite RT (MA) & $-.21^{*}$ & $.05^{*}$ & $-.36^{* *}$ & $.11^{* *}$ & $-.29^{* *}$ & $.07^{* *}$ \\
\hline
\end{tabular}

Note. TONI-4 = Test of Nonverbal Intelligence -4 th Edition; PPVT-4 = Peabody Picture Vocabulary Test-4; CTOPP = Comprehensive Test of Phonological Processing; TOWRE SWE = Sight Word Efficiency subtest of the Test of Word Reading Efficiency; GORT-4 = Gray Oral Reading Test-4; WRMT-R = Woodcock Reading Mastery Test-Revised; MA = morphological awareness

${ }^{\mathrm{a}}$ GORT-4 Fluency composite scores. ${ }^{\mathrm{b}}$ Passage Comprehension subtest.

${ }^{*} p<.05 ;{ }^{* *} p<.01$.

Table 6. Results of hierarchical regression analyses predicting text-level reading outcomes with word reading accuracy variable as an additional predictor variable

\begin{tabular}{|c|c|c|c|c|c|}
\hline \multirow[t]{2}{*}{ Steps } & \multirow[t]{2}{*}{ Predictors } & \multicolumn{2}{|c|}{$\begin{array}{c}\text { Text reading fluency } \\
\text { (GORT-4) }\end{array}$} & \multicolumn{2}{|c|}{$\begin{array}{c}\text { Text comprehension } \\
\text { (WRMT-R) }\end{array}$} \\
\hline & & $\beta$ & $\Delta \mathrm{R}^{2}$ & $\beta$ & $\Delta \mathrm{R}^{2}$ \\
\hline \multirow[t]{3}{*}{1.} & & & $.11 *$ & & $.08^{*}$ \\
\hline & Nonverbal IQ (TONI-4) & $.38 *$ & & $.36^{*}$ & \\
\hline & Grade & .06 & & .11 & \\
\hline 2. & Receptive vocabulary (PPVT-4) & $.79 * *$ & $.27 * *$ & $.84 * *$ & $.31 * *$ \\
\hline 3. & Phonemic awareness (CTOPP Elision) & $.41 * *$ & $.11 * *$ & $.44 * *$ & $.07 *$ \\
\hline 4. & Word reading accuracy (Word Identification) & $.81 * *$ & $.28 * *$ & $.71 * *$ & $.21 * *$ \\
\hline $5 \mathrm{a}$. & Composite accuracy (morphological awareness) & $.21 *$ & $.05^{*}$ & $.29 *$ & $.02 *$ \\
\hline $5 \mathrm{~b}$. & Composite RT (morphological awareness) & $-.39 *$ & $.06^{*}$ & $-.31 *$ & $.02 *$ \\
\hline
\end{tabular}

Note. TONI-4 = Test of Nonverbal Intelligence - 4th Edition; PPVT-4 = Peabody Picture Vocabulary Test-4; CTOPP = Comprehensive Test of Phonological Processing; GORT-4 = Gray Oral Reading Test-4; WRMT-R = Woodcock Reading Mastery Test-Revised.

${ }^{*} p<.05 ; * * p<.01$. 
The first three steps accounted for between 27 to $46 \%$ of the unique variance of the outcome variables. Consistent with previous research (Beck \& McKeown, 1990; Torgesen, Rashotte, \& Alexander, 2001), vocabulary contributed a significant amount of variance in text reading fluency (27\%) and text comprehension (31\%). Most importantly, the hierarchical regression analyses revealed first that the RT composite explained unique variance for all reading variable after controlling for the effects nonverbal IQ, grade, vocabulary, and phonemic awareness. Specifically, the highest amount was for the GORT-4 scores $(11 \%, p<.01)$, a task most clearly requiring rapid and automatic morphological decomposition of multimorphemic words. The second amount was for the Passage Comprehension subtest $(7 \%, p<.01)$ and the lowest ( 4 to $5 \%, p<.05$ ) was for the word reading fluency subtest (i.e., TOWRE), which contained very few derivational word items. Further, the accuracy composite explained a comparable amount of variance in Passage Comprehension scores $(7 \%, p<.01)$ and an only slightly smaller variance in GORT-4 scores $(9 \%, p<.01)$. By contrast, the RT composite scores accounted for a smaller amount of unique variance in word-level reading fluency (5\%), but accuracy composite scores made no significant contribution to word reading fluency variables. This suggests that the effects of morphological awareness skills were larger for the text-level measures than the word reading fluency measure.

Two further hierarchical regression analyses explored whether the morphological awareness skills affected text reading fluency and reading comprehension above and beyond the effects of word reading accuracy. All variables were entered in the same order as previous analyses except that the word reading accuracy scores (i.e., Word Identification) were entered in Step 4. Thus, morphological awareness composite scores were entered in Step 5a and Step 5b. Table 6 displays the results of these two analyses. In both analyses, morphological awareness still accounted for a small but significant amount of variance in text-level reading measures in each analysis (4 to 5\%), indicating that it contributes to text-level reading above and beyond the effect of word reading accuracy.

\section{Discussion}

In this investigation, we measured both accuracy and speed (RTs) components of morphological processing to test whether Spanish-speaking language-minority students from low SES backgrounds perform derivational morphological awareness tasks with the same facility as their English only classmates. We also explored the extent to which morphological awareness skills contributed to reading fluency (word- and text-level) and reading comprehension skills of bilingual participants using two written tasks of morphological production: Morpheme Blending and Morpheme Generation.

Previous morphological awareness research has exclusively focused on understanding the effects of morphological awareness accuracy on reading comprehension, primarily through the mediating role of vocabulary. This is obviously an important endeavor: in the data reported here, which converge with numerous previous reports, we find that vocabulary contributes approximately one third of the variance to reading fluency (29\%) and to reading comprehension (31\%). Beyond the effects of vocabulary, however, our results show that Spanish-English bilinguals were significantly less accurate than their monolingual classmates on both morphological awareness tasks when the participants' grade was controlled. A slightly larger effect size was obtained for the contextualized task (i.e., Morpheme Generation), presumably because of higher levels of linguistic subskills that are required to process the semantic information of words, contextual knowledge, and syntactic knowledge. We also found that the accuracy component of morphological awareness makes unique contributions to text processing - both fluency $(9 \%)$ and comprehension $(7 \%)$ - but not to single word reading fluency. These results are consistent with studies that reported similar amounts of variance of textlevel tasks had been explained by morphological awareness accuracy (Kirby et al, 2012).

An additional series of questions in the present study concerned the extent to which morphological processing efficiency, defined here as speed of accurate responses, contributes to outcome measures of reading fluency and comprehension. We report two main findings. First, bilingual participants processed this morphological information significantly slower than their English-only classmates even though many bilingual participants' morphological processing accuracy scores reached ceiling (i.e., $92 \%$ for Morpheme Blending task and $84 \%$ for Morpheme Generation task, respectively). Indeed, the effect sizes of group differences were larger for the RT measures than for accuracy measures. Secondly, over and above the effects of phonological awareness and controlling for the effects of nonverbal IQ, grade, vocabulary, speed with which bilingual readers processed morphological units makes significant contributions to both text reading fluency $(11 \%)$ and text comprehension (7\%). Considering the number of our control variables in the regression analyses, this was a substantial contribution. We also found that morphological processing efficiency continued to have significant effects on text-based tasks above and beyond the effects on word reading accuracy (see Table 6), albeit small ones in terms of variance explained (4 to 6\%). Thus, our data extends the previous research by demonstrating that morphological processing latency (or efficiency) is another vital construct of morphological processing that is as important to text-level reading skills as the accuracy component, especially in the upper grades.

\section{Theoretical and Practical Implications}

As the findings presented here reveal the unique and significant role that morphological processing efficiency plays in reading comprehension, we concur with several researchers who have implicated previous versions of Perfetti's lexical quality hypothesis (LQH; Perfetti \& Hart, 2001) as a useful framework for investigating the role of morphological knowledge in reading comprehension. The LQH emphasizes that comprehension of text is intricately related to the quality of multiple representational features of lexical items, including orthographic, semantic, and phonological information. The general implication of this is that strong representations of words allows for efficient "low cost" processing at the lexical level (i.e., morphological decomposition), which frees up "high cost" cognitive resources needed for text integration and comprehension. 
Relatedly, Taft (2004) argued that decomposition of words into morphemic constituents during text reading is required for all multimorphemic words (see also Caramazza, Laudanna, and Romani, 1988, for an earlier discussion). Studies investigating processing of written morphology have also demonstrated that efficient decomposition of printed words into morphemes heavily relies on the quality of orthographic representations of morphemic units of words (Rastle \& Davis, 2008). Thus, poor orthographic representations are often implicated as being causally related to difficulties in morphological decomposition, leading to both fluency and comprehension problems in children who have amassed much less reading experience than their peers. Bilingual children from low SES backgrounds may have underdeveloped orthographic representations because of their lack of rich experience with text that is critical to the development of high quality orthographic representations and this may explain why bilingual children in our sample were outperformed by monolingual control children on both accuracy and speed measures of morphological awareness.

Further, bilingualism creates additional, unique constraints, as well. It is often reported that bilinguals perform slower than monolinguals on lexical retrieval tasks due to competition that arises between simultaneous activation of two competing lexicons (Grosjean, 2001; Marian \& Spivey, 2003). Such competition, by itself, could also be the source of lexical interference, which in turn has negative effects on fluency and comprehension. In addition to the competition inherent to processing two languages, however, we conjecture that there may be something very specific about derivational morphology which adds to this competition at the lexical level. By definition, words with derivational morphology are derived from other words. Derived forms such as likely, liken, likelihood, and likeness, for example, are minimally differentiated from one another in terms of their orthographic, phonological, and semantic representations. So, while all readers must negotiate the interference created by derived word forms, this additional interference may become additive in bilingual readers who may have relatively impoverished sensitivity to orthographic features of words.

If this is the case, and if lexical quality is developed through contextual reading experience, it is quite possible that bilinguals need more experience (i.e., more practice) processing words with derivational morphology than their monolingual peers. This remains a question for future research. Findings from this study suggest that beyond implementing structural analysis work, which focuses on understanding the meaning components of morphological units, interventions targeting morphological processing speed may prove to be an important additional focus of instruction for low SES bilinguals. Goodwin and Ahn (2010) found that morphological awareness treatment has significant moderate effects on a variety of reading outcome measures, including improved morphological awareness, phonological awareness, and vocabulary; however, effect sizes for reading comprehension were not as robust. Our data suggest that reading comprehension could be enhanced by improving morphological processing speed. In two recently meta-analyses which examined the effects of morphological treatment on a number of reading outcomes (Bowers, Kirby, \& Deacon, 2010; Goodwin \& Ahn, 2010), a variety of morphological awareness treatment paradigms were evaluated (e.g., identifying patterns and rules of morphological units and relating morphology to vocabulary and grammar); yet, none of these included treatment focused specifically on improving morphological processing fluency. Thus, this is an area of reading intervention that currently seems to be lacking.

\section{Limitations and Future Directions}

A few limitations are of note. The first concerns our outcome measures. Because all of our morphological tasks were timed, accuracy scores were derived under time constraints. While this methodology renders the most valid morphological processing efficiency scores, and yielded accuracy findings that were consistent with previous research, it may have affected the total number of accurate responses and/or biased the findings to artificially align with reading outcome measures that were also timed (i.e., text reading fluency). Future studies should perhaps use multiple morphological processing measures, both timed and untimed. Second, with respect to the hypothesis that poor lexical representation of morphological units are related to morphological processing in bilinguals, the effects of orthographic knowledge, along with phonological and semantic knowledge should be considered. Third, along with Kieffer et al. (2013) we also interpret the relationship between morphological processing and single word reading with caution because the task used (i.e., TOWRE Sight Word Efficiency) contains very morphologically complex words. In future studies, we suggest that a single word reading task also include more morphologically complex words.

Despite these limitations, results from this investigation are in line with many recent studies which show that morphological processing is an important sub-skill of reading for students transitioning into the middle school years. We found that for text reading fluency and reading comprehension, morphological processing speed contributes at least equally to the contributions made by morphological processing accuracy. Because morphological processing speed makes significant unique contributions to text reading fluency and comprehension, an important subject of future research is to examine the effects of fluency practice on reading comprehension using morphologically complex words.

\section{References}

Abu-Rabia, S., Share, D., \& Mansour, M. (2003). Word recognition and basic cognitive processes among readingdisabled and normal readers in Arabic. Reading and Writing: An Interdisciplinary Journal, 16, 423-442. http://dx.doi.org/10.1023/A:1024237415143

American National Standards Institute. (1989). American National Standard specifications for audiometers (ANSI S3.61989). New York: Acoustical Society of America. http://dx.doi.org/10.1044/0161-1461(2009/08-0015) 
Apel, K., \& Thomas-Tate, S. (2009). Morphological awareness skills of fourth-grade African American students. Language, Speech, and Hearing Sciences in Schools, 40, 312-324.

August, D., \& Shanahan, T. (2006). Developing literacy in second language learners: Report of the national literacy panel on language minority youth and children. Mahwah, NJ: Erlbaum.

Beck, I. \& McKeown, M. (1990). Conditions of vocabulary acquisition. In R. Barr, M. L. Kamil, P. B. Mosenthal, \& P. D. Pearson (Eds.), Handbook of Reading Research (Vol. 2, 789-814). New York: Longman.

Bowers, P. N., Kirby, J. R., \& Deacon, S. H. (2010). The effects of morphological instruction on literacy skills: A systematic review of the literature. Review of Educational Research, 80, 144-179. http://dx.doi.org/10.3102/0034654309359353

Brown, L., Sherbenou, R. J., \& Johnsen, S. K. (2010). Test of nonverbal intelligence (4th ed.). Austin, TX: PRO-ED.

Caramazza, A., Laudanna, A., \& Romani, C. (1988). Lexical access and inflectional morphology. Cognition, 28, 297332. http://dx.doi.org/10.1016/0010-0277(88)90017-0

Carlisle, J. F. (1995). Morphological awareness and early reading achievement. In L. Feldman (Ed.), Morphological aspects of language processing (pp. 189-209). Hillsdale, NJ England: Lawrence Erlbaum Associates, Inc.

Carlisle, J. F. (2000). Awareness of the structure and meaning of morphologically complex words: Impact on reading. Reading and Writing: An Interdisciplinary Journal, 12, 169-190. http://dx.doi.org/10.1023/A:1008131926604

Carlisle, J. F. (2003). Morphology matters in learning to read: A commentary. Reading Psychology, 24, 291-322. http://dx.doi.org/10.1080/02702710390227369

Carlisle, J. F. (2007). Fostering morphological processing, vocabulary development, and reading comprehension. In R. K. Wagner, A. E. Muse, \& K. R. Tannenbaum (Eds.), Vocabulary acquisition: Implications for reading comprehension (pp. 78-103). NY: Guilford Press.

Carlisle, J. F., \& Katz, L. (2006). Effects of word and morpheme familiarity on reading of derived words. Reading and Writing: An Interdisciplinary Journal, 19, 669-693. http://dx.doi.org/10.1007/s11145-005-5766-2

Carlo, M., August, D., McLaughlin, B., Snow, C., Dressler, C., Lippman, D., Lively, T., \& White, C. (2004). Closing the gap: Addressing the vocabulary needs of English language learners in bilingual and mainstream classrooms. Reading Research Quarterly, 39, 188-215. http://dx.doi.org/10.1598/RRQ.39.2.3

Casalis, S.,Colé, P., \& Sopo, D. (2004). Morphological awareness and dyslexia. Annals of Dyslexia, 54, 114-138. http://dx.doi.org/10.1007/s11881-004-0006-z

Cohen, J. (1988). Statistical power analysis for the behavioral sciences (2nd ed.). Hillsdale, NJ: Erlbaum.

Deacon, S. H. (2011). Sounds, letters and meanings: The independent influences of phonological, morphological and orthographic skills on early word reading accuracy. Journal of Research in Reading, 35, 456-475. http://dx.doi.org/10.1111/j.1467-9817.2010.01496.x

Deacon, S. H., \& Kirby, J. R. (2004). Morphological awareness: Just "more phonological”? The roles of morphological and phonological awareness in reading development. Applied Psycholinguistics, 25, 223-238. http://dx.doi.org/10.1017/S0142716404001110

Derwing, B. L., Smith, M. L., \& Wiebe, G. E. (1995). On the role of spelling in morpheme recognition: Experimental studies with children and adults. In L. B. Feldman (Ed.), Morphological aspects of language processing (pp. 3-27). Hillsdale, NJ: Lawrence Erlbaum Associates, Inc.

Dowhower, S. (1987). Aspects of repeated reading on second-grade transitional readers fluency and comprehension. Reading Research Quarterly 22, 389-406. http://dx.doi.org/10.2307/747699

Dunn L. M., Padilla, E. R., Lugo, D. E., \& Dunn, L. M. (1986). Test de Vocabulario en Imágenes Peabody (TVIP). Circle Pines, MN: AGS Publishing.

Dunn, L. M., \& Dunn, L. M. (2006). Peabody Picture Vocabulary Test (4th ed.). Bloomington, MN: Pearson Education. Empirisoft Corporation (2012). User's Guide and Reference MediaLab v2012. New York: Empirisoft Corporation.

Fowler, A. E., \& Liberman, I. Y. (1995). The role of phonology and orthography in morphological awareness. In L. Feldman (Ed.), Morphological aspects of language processing (pp. 157-188). Hillsdale, NJ England: Lawrence Erlbaum Associates, Inc.

Fuchs, L.S., Fuchs, D., Hosp, M.K., \& Jenkins, J.R. (2001). Oral reading fluency as an indicator of reading competence: A theoretical, empirical, and historical analysis. Scientific Studies of Reading, 5, 239-256. http://dx.doi.org/10.1207/S1532799XSSR0503_3

Goodwin, A. P., \& Ahn, S. (2010). A meta-analysis of morphological interventions: Effects on literacy achievement of children with literacy difficulties. Annals of Dyslexia, 60, 183-208. http://dx.doi.org/10.1007/s11881-010-0041-x

Goodwin, A. P., Huggins, A., Carlo, M., Malabonga, V., Kenyon, D., Louguit, M., \& August, D. (2011). Development and validation of extract the base: An English derivational morphology test for third through fifth grade monolingual students and Spanish-speaking English language learners. Language Testing, 29, 265-289. http://dx.doi.org/10.1177/0265532211419827 
Grosjean, F. (2001). The bilingual's language modes. In J. Nicol (ed.),One mind, two languages: Bilingual language processing (pp. 1-22). Oxford: Blackwell.

Hernandez, D. J., Denton, N., \& Macartney, S. E. (2007). Children in immigrant families-The U.S. and 50 States: National origins, language, and early education. Albany, NY: Center for Social and Demographic Analysis, University at Albany, SUNY.

Hollingshead, A. A. (1975). Four-factor index of social status. Unpublished manuscript, Yale University, New Haven, CT.

Jia, G., Kohnert, K., Collado, J. \& Aquino-Garcia, F. (2006) Action naming in Spanish and English by sequential bilingual children and adolescents. Journal of Speech Language, and Hearing Research, 49, 588-602. http://dx.doi.org/10.1044/1092-4388(2006/042)

Kieffer, M. J., \& Lesaux, N. K. (2008). The role of derivational morphological awareness in the reading comprehension of Spanish-speaking English language learners. Reading and Writing: An Interdisciplinary Journal, 21, 783-804. http://dx.doi.org/10.1007/s11145-007-9092-8

Kieffer, M. J., \& Lesaux, N. K. (2010). Morphing into adolescents: Active word learning for English language learners and their classmates in middle school. Journal of Adolescent \& Adult Literacy, 54, 47-56. http://dx.doi.org/10.1598/JAAL.54.1.5

Kieffer, M. J., \& Lesaux, N. K. (2012). Development of morphological awareness and vocabulary knowledge for Spanish-speaking language minority learners: A parallel process growth model. Applied Psycholinguistics, 33, 25-54.

Kieffer, M. J., Biancarosa, G., \& Mancilla-Martinez, J. (2013). Roles of morphological awareness in English reading comprehension for Spanish-speaking language minority learners: Exploring partial mediation by vocabulary and reading fluency. Applied Psycholinguistics, 34, 697-725. http://dx.doi.org/10.1017/S0142716411000920

Kirby, J. R., Deacon, S. H., Bowers, P. N., Izenberg, L., Wade-Woolley, L., \& Parrila, R. (2012). Children's morphological awareness and reading ability. Reading and Writing: An Interdisciplinary Journal, 25, 389-410. http://dx.doi.org/10.1007/s11145-010-9276-5

Koda, K. (2008). Impacts of prior literacy experience on second language learning to read. In Koda \& A. Zehler (Eds.), Learning to Read Across Languages. Cross-Linguistic Relationships in First and Second-Language Literacy Development (pp. 68-96). New York: Routledge.

Koda, K., Takahashi, E., \& Fender, M. (1998). Effects of L1 processing experience on L2 morphological awareness. Ilha do Desterro, 35, 59-87.

Kohnert, K. J., Bates, E., \& Hernandez, A. E. (1999). Balancing bilinguals: Lexical-semantic production and cognitive processing in children learning Spanish and English. Journal of Speech, Language, and Hearing Research, 42, 14001413.

Kuo, L., \& Anderson, R. C. (2006). Morphological Awareness and Learning to Read: A Cross-Language Perspective. Educational Psychologist, 41, 161-180. http://dx.doi.org/10.1207/s15326985ep4103_3

Leong, C. K. (2000). Rapid processing of base and derived forms of words and grades 4, 5, and 6 children's spelling. Reading and Writing: An Interdisciplinary Journal, 12, 277-302. http://dx.doi.org/10.1023/A:1008168902922

Lesaux, N. K. (2006). (with Koda, K., Siegel, L. S. \& Shanahan, T). Development of literacy in language minority learners. In D. L. August \& T. Shanahan (Eds.), Developing literacy in a second language: Report of the National Literacy Panel (pp. 75-122.) Mahwah, NJ: Erlbaum. http://dx.doi.org/10.3102/0002831209355469

Lesaux, N. K., \& Kieffer, M. J. (2010). Exploring sources of reading comprehension difficulties among language minority learners and their classmates in early adolescence. American Educational Research Journal, 47, 596-632.

Mahony, D. (1994). Using sensitivity to word structure to explain variance in high school and college level reading ability. Reading and Writing: An Interdisciplinary Journal, 6, 19-44.

Marian, V. \& Spivey, M. (2003). Comparing bilingual and monolingual processing of competing lexical items. Applied Psycholinguistics, 24, 173-193. http://dx.doi.org/10.1023/A:1008136012492

McBride-Chang, C., Shu, H., Ng, J. Y. W., Meng, X., \& Penney, T., (2007). Morphological structure awareness, vocabulary, and reading. In R. K. Wagner, A. E. Muse, \& K. R. Tannenbaum (Eds.), Vocabulary acquisition: Implications for reading comprehension (pp. 104-122). New York, NY: Guilford Press.

Menken, K. (2008). English Learners Left Behind: Standardized Testing as Language Policy. Toronto: Multilingual Matters.

Nagy, W. E., Kuo-Kealoha, A., Wu, X., Li, W., Anderson, R. C., \& Chen, X. (2002). The role of morphological awareness in learning to read Chinese. In W. Li, J. S. Gaffney, \& J. L. Packard (Eds.), Chinese language acquisition: Theoretical and pedagogical issues (pp. 59-86). Norwell, MA: Kluwer.

Nagy, W. E., Osborn, J., Winsor, P. \& O’Flahavan, J. (1994). Structural analysis: Some guidelines for instruction. In F. Lehr and J. Osborn (Eds.), Reading, language, and literacy: Instruction for the twenty-first century (pp. 45-58). Hillsdale, New Jersey: Erlbaum. 
Nagy, W., Berninger, V. W., \& Abbott, R. D. (2006). Contributions of morphology beyond phonology to literacy outcomes of upper elementary and middle-school students. Journal of Educational Psychology, 98, 134-147. http://dx.doi.org/10.1037/0022-0663.98.1.134

Nagy, W., Berninger, V., Abbott, R., Vaughan, K., \& Vermeulen, K. (2003). Relationship of morphology and other language skills to literacy skills in at-risk second grade readers and at-risk fourth grade writers. Journal of Educational Psychology, 95, 730-742. http://dx.doi.org/10.1037/0022-0663.95.4.730

Park, J. \& Lombardino, L. J. (2012). A Comparison of Phonological Processing Skills of Children With Mild to Moderate Sensorineural Hearing Loss and Children With Dyslexia. American Annals of the Deaf, 157, 289-306. http://dx.doi.org/10.1353/aad.2012.1621

Park, J. \& Lombardino, L. J. \& Ritter, M. (2013). Phonology Matters: A Comprehensive Investigation of Reading and Spelling Skills of School-Age Children With Mild to Moderate Sensorineural Hearing Loss. American Annals of the Deaf, 158, 20-40. http://dx.doi.org/10.1353/aad.2013.0013

Pasquarella, A., Chen, C., Lam, K., Luo, Y. C., \& Ramirez, G. (2011). Cross-language transfer of morphological awareness in Chinese-English bilinguals. Journal of Research in Reading, 34, 23-42. http://dx.doi.org/10.1111/j.14679817.2010.01484.x

Perfetti, C. A. (1988). Verbal efficiency theory in reading ability. In M. Daneman, G. E. MacKinnon, \& T. G. Waller (Eds.), Reading Research: Advances in Theory and Practice (pp. 109-143). New York: Academic Press.

Perfetti, C. A., \& Hart, L. (2001). The lexical bases of comprehension skill. In D. S. Gorfien (Ed.), On the consequences of meaning selection: Perspectives on resolving lexical ambiguity (pp. 67-86). Washington, DC: American Psychological Association. http://dx.doi.org/10.1037/10459-004

Ramirez, G., Chen-Bumgardner, B., Geva, E., \& Kiefer, H. (2010). Morphological awareness in Spanish-English bilingual children: within and cross-language effects on word reading. Reading and Writing, 23, 337-358. http://dx.doi.org/10.1007/s11145-009-9203-9

Ramirez, G., Chen-Bumgardner, B., Geva, E., \& Luo, Y. (2011). Morphological awareness and vocabulary in ELLs. Applied Psycholinguistics, 32, 601-618. http://dx.doi.org/10.1017/S0142716411000233

Rastle, K. \& Davis, M. H. (2008). Morphological decomposition based on the analysis of orthography. Language and Cognitive Processes, 23, 942-971. http://dx.doi.org/10.1080/01690960802069730

Reardon, S. F., \& Galindo, C. (2006). Patterns of Hispanic students' math and English literacy test scores in the early elementary grades. Tempe, AZ: National Task Force on Early Childhood Education for Hispanics.

Roman, A. A., Kirby, J. R., Parrila, R. K., Wade-Woolley, L. L., \& Deacon, S. H. (2009). Toward a comprehensive view of the skills involved in word reading in grades 4, 6, and 8. Journal Of Experimental Child Psychology, 102, 96113. http://dx.doi.org/10.1016/j.jecp.2008.01.004

Semel, E. M., Wiig, E. H., \& Secord, W. A. (2003). Clinical Evaluation of Language Fundamentals (4th ed.). San Antonio, TX: The Psychological Corporation.

Snow, C., Burns, S., \& Griffin, P. (Eds.). (1998). Preventing Reading Difficulties in Young Children. Washington, DC: National Academy Press.

Shu, H., McBride-Chang, C., Wu, S., \& Liu, H. (2006). Understanding Chinese developmental dyslexia: Morphological awareness as a core cognitive construct. Journal of Educational Psychology, 98, 122-133. http://dx.doi.org/10.1037/0022-0663.98.1.122

Singson, M., Mahony, D. \& Mann, V. (2000). The relation between reading ability and morphological skills: Evidence from derivation suffixes. Reading and Writing: An Interdisciplinary Journal, 12, 219-252. http://dx.doi.org/10.1023/A:1008196330239

Strong, A. C., Wehby, J. H., Falk, K. B., \& Lane, K. L. (2004). The impact of a structured reading curriculum and repeated reading on the performance of junior high students with emotional and behavioral disorders. School Psychology Review, 33, 561-581.

Taft, M. (2004). Morphological decomposition and the reverse base frequency effect. Quarterly Journal of Experimental Psychology, 57, 745-765.

Taft, M., \& Kougious, P. (2004). The processing of morpheme-like units in monomorphemic words. Brain and Language, 90, 9-16. http://dx.doi.org/10.1016/S0093-934X(03)00415-2

Tong, X., Deacon, S., Kirby, J. R., Cain, K., \& Parrila, R. (2011). Morphological awareness: A key to understanding poor reading comprehension in English. Journal of Educational Psychology, 103, 523-534. http://dx.doi.org/10.1037/a0023495

Torgesen, J. K., Rashotte, C. A., \& Alexander, A. W. (2001). Principles of fluency instruction in reading: Relationships with established empirical outcomes. In M. Wolf (Ed.), Dyslexia, fluency and the brain (pp. 333-355). Timonium, MD: York Press.

Tractenberg, R. E. (2002). Exploring hypotheses about phonological awareness, memory, and reading achievement. Journal of Learning Disabilities, 35, 407-424. http://dx.doi.org/10.1177/00222194020350050201 
Verhoeven, L., Baayen, H., \& Schreuder, R. (2004). Orthographic constraints and frequency effects in complex word identification. Written language and literacy, 7, 49-59. http://dx.doi.org/10.1075/wll.7.1.06ver

Wagner, R., \& Torgesen, J. (1987). The nature of phonological processes and its causal role in the acquisition of reading skills. Psychological Bulletin, 101, 192-212. http://dx.doi.org/10.1037/0033-2909.101.2.192

Wagner, R., Torgesen, J., \& Rashotte, C. (1999a). Test of Word Reading Efficiency: Examiner's manual. Austin, Texas: Pro-Ed.

Wagner, R., Torgesen, J., \& Rashotte, C. (1999b). Comprehensive Test of Phonological Processing: Examiner's Manual. Austin, Texas: Pro-Ed.

Wiederholt, J., \& Bryant, B. (2001). Gray Oral Reading Tests ( ${ }^{\text {th }}$ edition). Austin, Texas: Pro-ed.

Woodcock, R. (1998). Woodcock Reading Mastery Tests-Revised. American Guidance Service. Minnesota: Circle Pines.

Zhang, D., \& Koda, K. (2012). Contribution of morphological awareness and lexical inferencing ability to L2 vocabulary knowledge and reading comprehension among advanced EFL learners: Testing direct and indirect effects. Reading and Writing: An Interdisciplinary Journal, 25, 1195-1216. http://dx.doi.org/10.1007/s11145-011-9313-z

Zhang, J., Anderson, R.C., Li, H., Dong, Q., Wu, X. \& Zhang, Y. (2010). Cross-language transfer of insight into the structure of compound words. Reading and Writing: An Interdisciplinary Journal, 23, 311-336. http://dx.doi.org/10.1007/s11145-009-9205-7

\section{Appendix A. Test items on the Morpheme Blending task}

\begin{tabular}{|c|c|c|}
\hline 1. $\quad$ sing & er & \\
\hline 2. certain & un & \\
\hline 3. like & dis & \\
\hline 4. possible & im & ity \\
\hline 5. ence & exist & \\
\hline 6. able & comfort & \\
\hline 7. happy & un & ness \\
\hline 8. accept & un & able \\
\hline 9. ment & agree & dis \\
\hline 10. understand & mis & \\
\hline 11. able & un & comfort \\
\hline 12. courage & dis & \\
\hline 13. ment & place & re \\
\hline 14. ly & friend & \\
\hline 15. ness & fool & ish \\
\hline 16. able & avail & \\
\hline 17. ful & success & ly \\
\hline 18. pre & view & \\
\hline 19. health & $\mathrm{y}$ & un \\
\hline 20. fear & ness & less \\
\hline 21. ness & fit & \\
\hline 22. ful & ly & care \\
\hline 23. al & arrive & \\
\hline 24. less & care & ness \\
\hline 25. possible & ity & \\
\hline 26. cover & dis & $\mathrm{y}$ \\
\hline 27. ly & polite & im \\
\hline 28. ation & educate & \\
\hline 29. ly & thank & ful \\
\hline 30. ness & faith & ful \\
\hline 31. un & able & \\
\hline 32. expect & un & ed \\
\hline 33. dom & free & \\
\hline 34. able & un & forgive \\
\hline 35. ary & second & \\
\hline 36. hood & neighbor & \\
\hline 37. move & re & al \\
\hline 38. honest & dis & \\
\hline 39. history & ly & ical \\
\hline 40. ship & friend & \\
\hline
\end{tabular}


Appendix B. Test items on the Morpheme Generation task
1. friend:
At school, I have a lot of
2. big:
The tiger was big, but the elephant was
3. quick:
Jonny had to finish homework
4. beauty:
That flower is
5. play:
My brother is a golf
6. run:
She is a great
7. friend:
Everybody likes John because he is very
8. mystery:
The dark glasses made the man look
9. success:
Last year, our business was quite
10. fame:
The singer was very
11. wash:
Put the laundry in the
12. science:
Einstein was a great
13. courage:
All of the soldiers were very
14. love:
Look at this dog. She is so
15. invent:
iPad is an amazing
16. free:
Thanks to our ancestors, America now has
17. create:
Thomas Edison was very
18. danger:
Driving a car during the night is very
19. attend:
Students were talking in class and not paying
20. color:
The rainbow was
21. decide:
Finally, Mr. President made a big
22. humor:
His joke was quite
23. believe:
John has a very strong in God.
24. fool:
Your decision was very 